\section{The bone marrow transplant clinical nurse specialist in hemato-oncology: an interview with Anthony Nolan Nurse Specialist Susan Paskar}

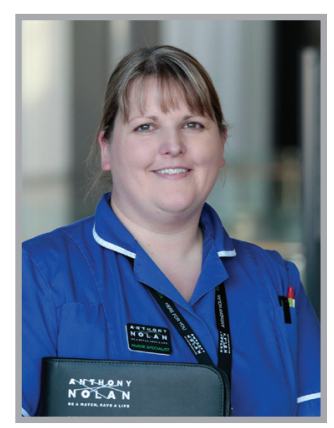

Susan Paskar* speaks to Sebastian Dennis-Beron, Commissioning Editor: Susan qualified in 1997 as a registered nurse and has 20 years of experience, in a range of specialties including hematology, medical and surgical oncology, general surgery, bariatric, breast, endocrine, head \& neck, liver, urology and bone marrow/ stem cell transplant. Working in both the UK and the USA, in regional transplant centers since 2002, she is considered expert in care of the bone marrow transplant patient from point of referral to long term follow-up care and palliation. She has been responsible for development and implementation of a Nurse-led late-effects post-bone marrow transplant service at the Freeman Hospital in Newcastle upon Tyne, as their Anthony Nolan Nurse Specialist.

Accepted for publication: 21 April 2017; Published online: 30 June 2017

Q Could you please provide a brief summary of your career to date? Did you always want to become a clinical nurse specialist?

I qualified as a nurse in 1997 from Leeds University (Leeds, UK), and worked on a general surgical ward in St James' Hospital (Leeds, UK). Interestingly, as a student nurse I was lucky enough to travel to California (USA) for 3 weeks with a small group to have a taste of work experience in the USA healthcare system. This visit led me to explore the possibility of future travel and working in the USA. I worked initially on a Hematology/ Oncology unit near Los Angeles (CA, USA), and later in Cedars Sinai Medical Center (Los Angeles, USA) on the Hematology/Oncology/Bone Marrow Transplant (BMT) Unit, where I had clinical experience of giving chemotherapy and looking after complex BMT patients. I gained qualifications as a chemotherapy provider, became an 'Oncology Certified Nurse', and completed my BSc in Nursing through the Royal College of Nursing and University of Manchester distance learning program.

Later, as I then had substantial BMT experience I was offered the opportunity to work as an Allogeneic Transplant Coordinator at City of Hope hospital in Duarte (CA, USA), which as well as developing my organizational skills, needed expert patient and family education. This was generally a fantastic environment to work in, with an inspirational team and world class care for the patients' it serves.

I spent over 11 years in California, before I made the decision to re-locate back to the UK. I applied for a BMT Clinical Nurse Specialist (CNS) post at the Freeman Hospital in Newcastle upon Tyne (Newcastle, UK), which was essentially an Allogeneic Transplant Coordinator role but also included looking after post-transplant patients. In 2014, the charity Anthony Nolan [1] offered our Trust funding to develop a post-transplant late

*Anthony Nolan Clinical Nurse Specialist, Newcastle upon Tyne Hospitals NHS Trust, UK Author for correspondence: s.dennis-beron@futuremedicine.com

\section{KEYWORDS}

- bone marrow transplant • clinical nurse specialist $\bullet$ hematologic cancers $\bullet$ palliative care 
effects service, so an Anthony Nolan BMT Nurse Specialist post was created, which I applied for and was able to start our nurse-led long-term BMT follow-up clinic. My career path leading to being a CNS was just a natural progression from the clinical experience gained over the years in each department I have worked in.

\section{Q How have you seen the management of hematologic malignancies develop over your career?}

It is almost hard to believe I will have been a qualified nurse for 20 years this year, but that means I have seen changes to how treatment of blood cancers is approached.

Targeted therapies, such as those used to treat chronic myeloid leukemia, allow many patients to achieve a durable remission from their disease, which means a transplant is no longer needed for the majority of patients. Immunotherapy and monitoring for disease at a molecular level are further examples of how blood cancers are being managed. DNA testing has been used to develop supportive drugs, (such as growth factors), and is essential to monitor engraftment after transplantation, to detect early relapse in these patients, or guide practitioners to manipulate the transplant to promote long term remission.

Q How important is the work being done by Anthony Nolan in terms of its impact to patients at a clinical level?

Essentially only $30 \%$ of patients who need a transplant will have a suitable donor in their family. We are dependent on Anthony Nolan to find matches for that remaining $70 \%$, so naturally the work of their donor teams is critical. The Anthony Nolan team is also working to make transplants more successful by looking at the mechanisms of the immune system which may be responsible for Graft versus Host Disease, and by working to detect molecular differences which may be responsible for graft rejection. This ground breaking research will translate at a patient level to less side effects and greater chance of long term disease-free survival. In recent years, Anthony Nolan has recognized the need to support patients after transplant, both with clinical symptoms, social and psychological support. Using expert CNSs in transplant centers, patient online forums and running patient education days are just some of the ways this support has been offered to patients.
Q How has your role changed since becoming a clinical nurse specialist with Anthony Nolan?

Working as a dedicated Late Effects Nurse Specialist has meant we could develop a service to better meet the needs of our Long Term Transplant patients, whose needs can be very different to an early post-transplant patient. Late effects, such as Chronic Graft versus HostDisease, secondary malignancies, palliation, social and psychological issues, are managed in a separate Nurse-Led clinic, which allows patients more time to discuss their problems and to manage these in a traditional medically led environment. Vitally, the creation of this separate service has created more capacity in our early post-BMT clinic, which would have not been able to cope with the growing cohort of post-transplant survivors.

\section{Q A lot of your work involves educating} colleagues on both clinical techniques \& supportive and palliative care: how important is this collaboration across departments to facilitate the needs of a patient?

One of the most important roles of any clinical nurse specialist will be to act as the patient's advocate, to help them make the best treatment decisions. The CNS will liaise with the medical team, will seek advice from or refer complex cases to allied healthcare professionals, to give patients the best chance of accessing the right treatment at the right time. With BMT being such a specialized field, it is sometimes necessary to give advice to General Practitioners, District Nurses and Social Workers, particularly in Medical Practices away from the Regional Transplant Centre, which may not necessarily have had prior experience of managing symptoms related to late effects of stem cell transplants.

Q Is having psychology training a key part of your role? Is this empathic understanding something you apply to both your patients \& your colleagues?

Having a good understanding of the psychological issues which commonly effect patients who have been through complex cancer treatment, such as a transplant, is essential to provide the correct level of support for patients and their families. I have previously undertaken level 2 psychology training; depression, anxiety, poor coping skills and even post-traumatic stress disorder are some examples of the types of problems that the CNS may have to manage. Not only can I offer support 
and a degree of counseling and symptom management, but it is vital to recognize when patients need intervention from level 3 qualified staff so would be referred to the clinical psychology team. In my BMT Late Effects clinic it is common for transplant patients who are physically well to be left with a legacy of psychological issues after long term treatment, and may need to face these in order to move on with their lives, many years after treatment.

\section{Q Could you tell our readers about the Anthony Nolan Patient Education Day you organized?}

Through the development of the nurse-led Transplant Late Effects service, common themes have emerged as frequent concerns of patients after their transplant. The team felt offering an education day to our patients, and their families was another opportunity to deliver this information. We invited a range of speakers to talk about topics relating to 'late effects' of transplant. We included advice on the management of both physical and mental fatigue, general money and benefits information from Citizen's Advice Bureau, relationship advice from a Newcastle Relate Charity counselor, as well as Medical speakers from the transplant team, which reflected the range of physical, social and psychological obstacles that our patients have to manage after their transplant.

It was just one of the Education Days supported by Anthony Nolan, which take place in different areas of the UK each year.

\section{Q What are the biggest challenges faced} today by clinical nurse specialists working in hematology?

Financial constraints on patient healthcare will be affecting services at all levels. Overall as the population is expanding and aging, and treatments are improving, the numbers of people living with and surviving blood cancers are growing. The CNSs are reviewing patients in greater numbers in clinics, and increasingly making clinical decisions which may have previously been made by the medical team. It is vital that CNSs continue to work within their 'scope of practice' and are competent to manage the patients under their care.

\section{References}

1 Anthony Nolan Website. www.anthonynolan.org (2017).
There is increasing justification for completing additional clinical skills training and nonmedical prescribing in some areas depending on the type of patient assessments they are expected to complete.

\section{Q Where do you see clinical care for blood} cancer patients in 5-10 years?

I am sure that targeted therapies and immunotherapies will continue to be developed and they will be the preferred option for the treatment of blood cancers, with the primary goal of long term remission with least side effects, which can be debilitating, and lifelong. I imagine the use of Haplo-identical transplantation will become more commonplace, as this method is becoming more accepted.

My major concern is the financial constraints within healthcare do not allow for the enormous amount of support that patients continue to need from all Allied Healthcare professionals throughout the transplant process. There are already inconsistencies in provision between different transplant centers nationwide, with currently only around $60 \%$ of UK transplant centers able to provide a 'late effects service' [2], which is why Anthony Nolan continues to advocate for better patient support, lobbying Government to understand the needs of this patient group, and by helping to establish Clinical Nurse Specialist posts across the countries to develop post-transplant patient provision.

\section{Disclaimer}

The opinions expressed in this interview are those of the interviewee and do not necessarily reflect the views of Future Medicine Ltd or any other institutions mentioned in the interview.

Financial \& competing interests disclosure

The author has no relevant affiliations or financial involvement with any organization or entity with a financial interest in or financial conflict with the subject matter or materials discussed in the manuscript. This includes employment, consultancies, honoraria, stock ownership or options, expert testimony, grants or patents received or pending, or royalties. No writing assistance was utilized in the production of this manuscript.

2 Hablin A, Greenfield D, Gilleece M et al. Provision of long-term monitoring and late effects services following adult allogeneic Q1 haematopoietic stem cell transplant: a survey of UK NHS-based programmes. Bone Marrow Transplant. (2017) (In press). 
